\title{
Evaluation of Helmet Protection during Impact of Head to Ground and Impact of an Object to Head Using Finite Element Analysis
}

\author{
Arnaldo Jacob, Caroline Faria, Gustavo Cardoso, Klebson Reis, Mariana Motta, \\ Thiago Meneghetti, Roberto Cammino*, Aiman Shibli \\ Illinois Institute of Technology, Chicago, USA
}

\begin{abstract}
This report describes the results of a research project focused on helmet protection under impact of head to ground, and impact of an object to head. Three kinds of helmets were considered: construction, motorcycle and bicycle helmets. The goal of this project is to check the amount of stress absorbed by the skull and brain during the impact, as well as evaluate the maximum capacity of helmet protection. The material used for each helmet was the most common material in the current market, in order to make the results more realistic. The analysis consists of dynamic simulation of an impact in the helmet using Finite Element Analysis (FEA). First, the models were meshed using Hypermesh. After the modeling phase, analyses were made using ABAQUS (a computer aided engineering program) that shows the stresses and displacements experienced by the whole system: helmet, skull and brain. The results obtained from the analysis were displayed on charts that show the effect of the helmet based on different boundary conditions such as object height for the hard hat, and the rider speed for the bicycle and motorcycle helmets.
\end{abstract}

Keywords Dynamic Finite Element, Impact, Safety Evaluations

\section{Introduction}

The usage of Personal Protective Equipment (PPE) is fundamental in several fields such as, construction, industry, and sports. There are many kinds of safety equipment such as gloves, clothes, glasses, and boots, hearing protectors, respirators and so on.

This research tries to model different situations in everyday life, and to show the importance of one essential PPE: the helmet. Three models were chosen to best describe the helmet action: bicycle, motorcycle and construction helmet.

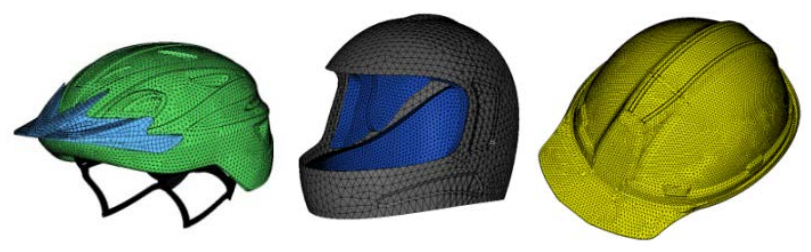

Figure 1. Helmet Models

The research focuses on the safety provided by helmets,

* Corresponding author:

cammino@iit.edu (Roberto Cammino)

Published online at http://journal.sapub.org/safety

Copyright (C) 2016 Scientific \& Academic Publishing. All Rights Reserved evaluating the maximum capacity of helmet protection, and the impact to the skull and the brain. In addition, it compares different shell materials:

- Acrylonitrile Butadiene Styrene (ABS), High Density Polyethylene (HDPE): for bike and construction helmets. [9]

- Carbon Fiber and Kevlar: for motorcycle helmets. [7]

The helmets were tested with these materials to analyze which ones have the best protection. We consider a helmet successful, when it avoids significant stresses in the brain and the skull in impact situations. The helmet must be strong enough to protect the head and light enough to not hinder the performance and comfort of the user.

In the majority of countries the use of motorcycle helmets is mandatory, however the United States is not covered by a nationwide law requiring motorcycle helmet use. Lives might be saved by using adequate helmets both for bikes and motorcycles, considering the average speed people ride their motorcycles is usually high. Helmets might also save lives at the construction field. In this case, there are rules to use helmets inside the work area. The helmet protects the workers against the impact of falling construction materials or objects. Indeed this project seeks to emphasize the helmet's efficiency in these scenarios.

The method utilized for this study is the Finite Element Analysis: a numerical approximation method also known as 
the Matrix Structural Analysis, due to its use of matrix algebra to solve systems of simultaneous equations. The Finite Element Analysis investigates the behavior of complex structures by breaking them down into smaller pieces, which consist of elements connected by nodes. After that, it is possible to assign the elements and compute stresses and displacements on the entire body. The simulations run in this paper are dynamic in nature, due to the impact cases analyzed.

\section{Methods}

To accomplish the tasks in this report, a few essential FEA tools were needed. The process of simulation follows three main steps:

\section{- Step 1: Preprocessing}

At this point, after deciding what kind of helmets would be simulated, a Computer Aided Design (CAD) model for a skull, a brain, and for each helmet were taken from an online database (Grabcad) [5]. In the pre-processing part, the software used in the analysis was Hypermesh. The models already in the appropriate extension (*.iges, ${ }^{*}$.prt, *.stp, *.igs, *.hm and some others) were imported into Hypermesh and the meshes were created. The mesh is created according to the problem so it can vary between $1 \mathrm{D}, 2 \mathrm{D}$ or $3 \mathrm{D}$ elements. In FEM, the meshes are the fundamental part for the whole process, because it is where the model is divided into small discrete elements. Constraints are also applied at this step.
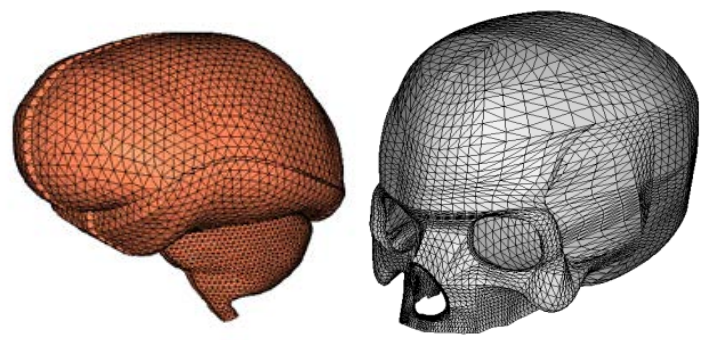

Figure 2. Mesh of brain and skull

\section{- Step 2: Processing}

Afterwards, when the model is totally meshed the second part of the process called processing begins. The input file exported from Hypermesh - now with the *.inp extension contains the code that describes all the model nodes and elements created.

In this phase, the elements are assigned its material and mechanical properties: Density, Young's Modulus, Poisson's Ratio, Ultimate and Yield Stresses. Most of the material properties data were taken from an online database (MatWeb). [1-4, 8, 10]

This phase also includes the definition of contact conditions (commands to tie components), and the thickness of shell and membrane components. The simulation considers the thickness of the skull as $2 \mathrm{~mm}$.

In addition, boundary conditions to the helmets are applied. These include: initial velocity and angle of impact for the bicycle and motorcycle helmets, and object drop height for hard hats.

At last, important information such as processing velocity and number of intervals are set at this point. After that, the file is ready to be used in ABAQUS, the program that will run all the analysis.

\section{- Step 3. Post Processing}

When all the procedures above are completed, the next step is the post-processing part, using ABAQUS Viewer to analyze the results obtained previously in the simulation. The displacement and stresses of the assembled body are the main data taken from this analysis.

Finally, one must note that these models do not have the ability to produce fracture, but rather assume the material will continue to deform. Therefore, it is only providing a qualitative assessment of the helmet protection of the brain and skull, however the results are still useful to indicate safety of helmet use and should be taken at face value. Naturally, if more exact models should be created, which include simulating fracture, that would be of value to helmet manufactures. This requires much more detailed skull designs and material models, which were not available to us and are beyond the scope of this work. The novelty, in this paper is to start considering brain modeling in future simulation and evaluation work. In addition, we do not look beyond the skull and brain, thus no additional parts of the body are analyzed, such as the spine or neck.

Table 1. Material Properties

\begin{tabular}{|l|l|l|l|l|l|l|}
\hline Property & HDPE & ABS & Carbon & Kevlar & Skull & Brain \\
\hline Density $\left(\mathbf{1 0}^{\mathbf{3}} \mathbf{g} / \mathbf{m m}^{\mathbf{3}}\right)$ & 0.95 & 1.02 & 1.43 & 1.440 & 1.5 & 1.04 \\
\hline Young's Modulus (MPa) & 900 & 1610 & 52 & 70.3 & 5000 & 1 \\
\hline Poisson's Ratio & 0.45 & 0.35 & 0.07 & 0.36 & 0.3 & 0.5 \\
\hline Yield Stress (MPa) & 26 & 37.3 & 48 & 60 & 110 & 0.02 \\
\hline Ultimate Stress (MPa) & 30.5 & 40 & 55 & 70.5 & 110 & 0.02 \\
\hline
\end{tabular}

\section{Results}

\section{- Construction Helmet Analysis}

Two objects were used in the construction helmet analysis: a plier and a brick. [12]

The impact conditions depend on the height that the object falling is hitting the head. The analysis considers three heights: $5 \mathrm{~m}$ (16.4ft), 20m (65.6ft), and 46m (150.9ft).

Considering the formula below:

$$
v^{2}=2 . g . H
$$

Where $\mathrm{v}$ is the final speed $(\mathrm{m} / \mathrm{s}), \mathrm{g}$ is the gravitational acceleration $\left(9.81 \mathrm{~m} / \mathrm{s}^{2}\right)$, and $\mathrm{H}$ is the height $(\mathrm{m})$.

Thus, the correspondent speeds are: $10 \mathrm{~m} / \mathrm{s}, 20 \mathrm{~m} / \mathrm{s}$, and $30 \mathrm{~m} / \mathrm{s}$. These speeds were applied as initial conditions to the objects falling on the head. 
This simulation shows the first $1.5 \mathrm{~ms}$ when the object (plier/brick) hits the head and for two materials: ABS and HDPE materials for the helmet shell. [9] For comparison purposes, we simulate the same cases, but without a helmet.

The figures and charts below show the values for stresses and displacements in the brain and the skull for different object drop heights.

In the first case, a standard set of pliers is simulated as a rigid body, impacting the helmet and the skull. The mass of the pliers is about 350 grams.

In the second case, a cinder block hitting the head and helmet is simulated. The block is also modeled as a rigid body and has a mass of 450grams.

\section{PLIER ANALYSIS RESULTS}
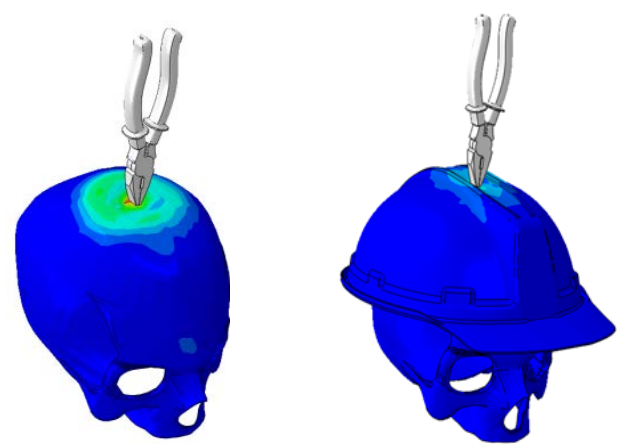

Figure 3. Plier Simulation representative figures Shell Stress vs Height

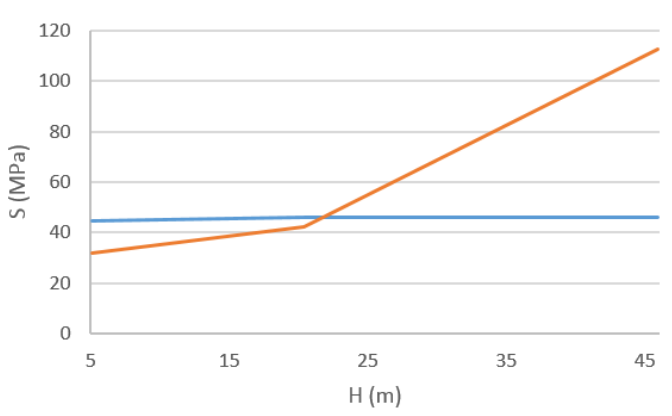

Shell Displacement vs Height

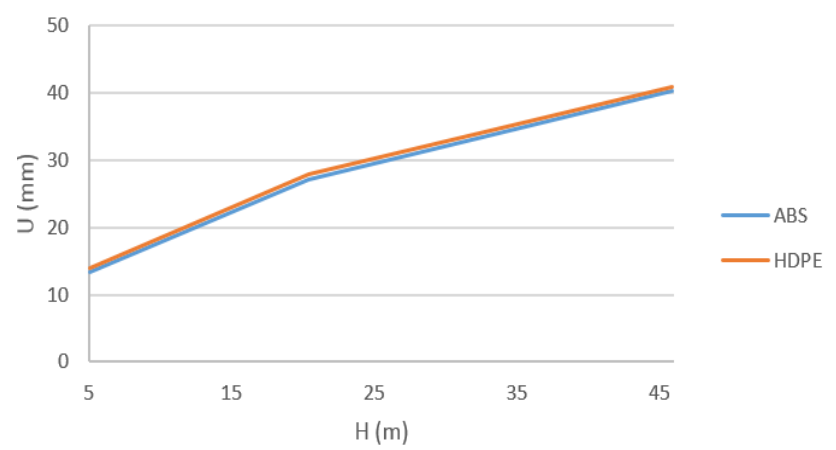

Skull Stress vs Height

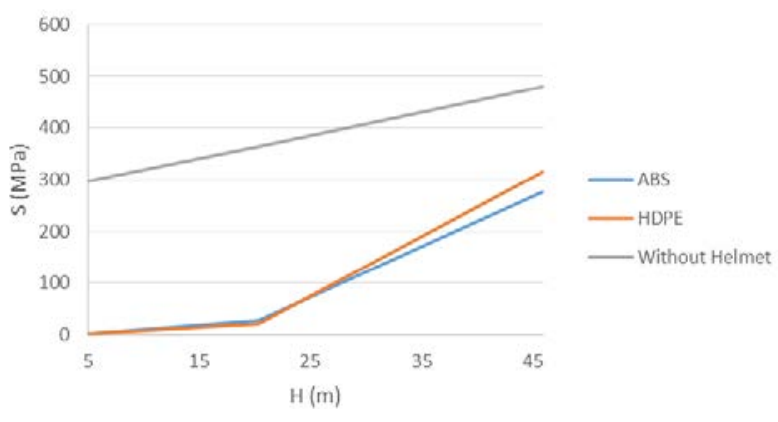

Skull Displacement vs Height

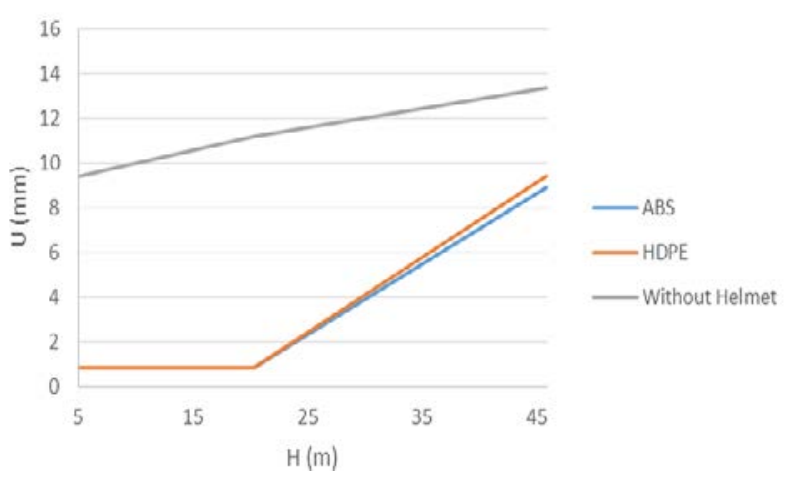

Brain Stress $x$ Height

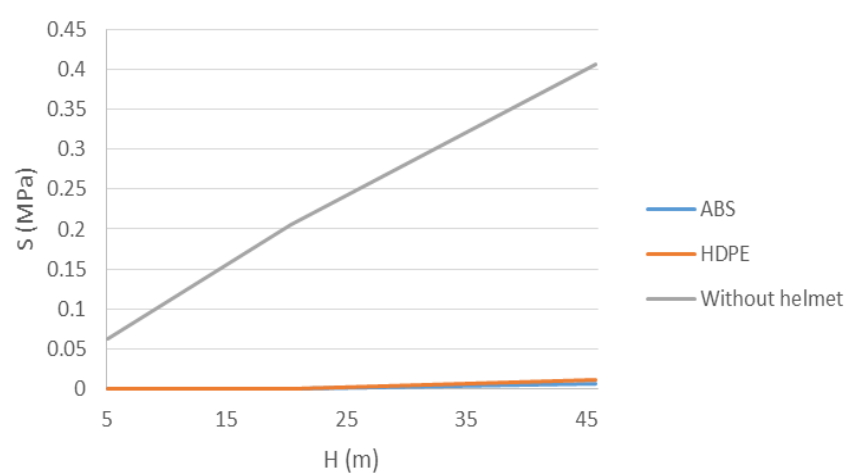

Brain Displacement vs Height

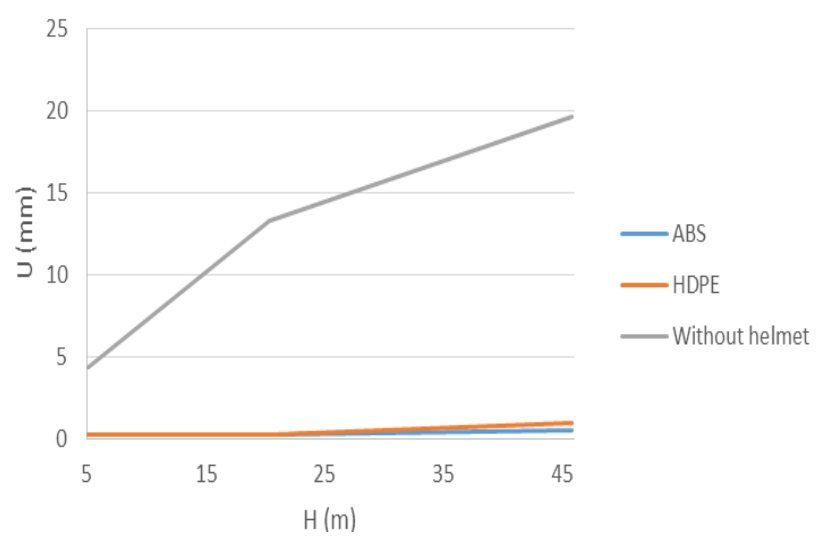


BRICK ANALYSIS RESULTS
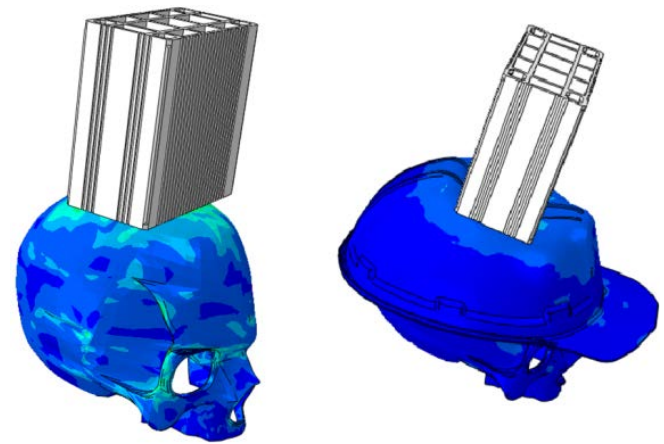

Figure 4. Brick Simulation representative figures

Skull Stress $x$ Height

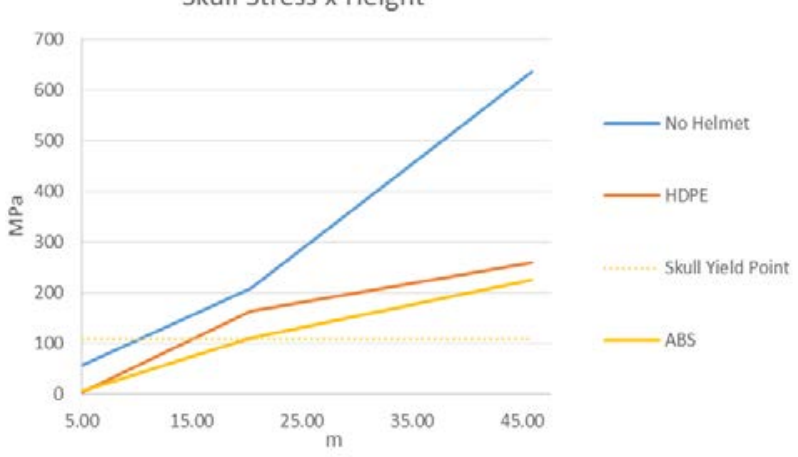

Skull Displacement $\mathrm{x}$ Height

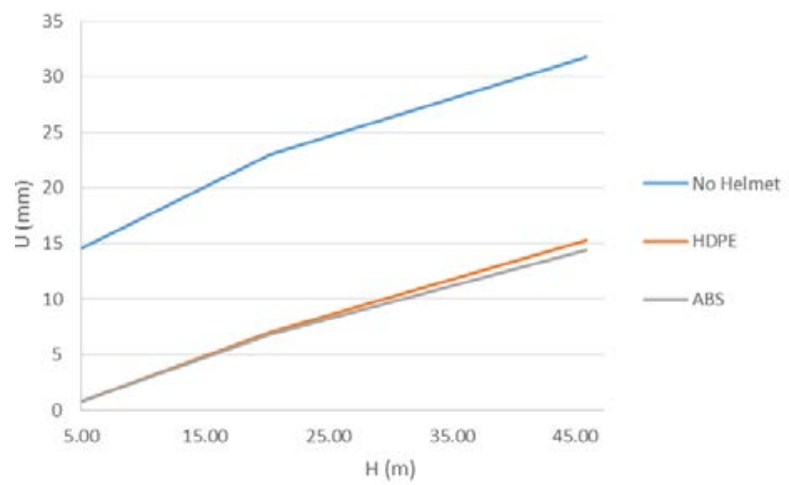

Brain Stress $x$ Height

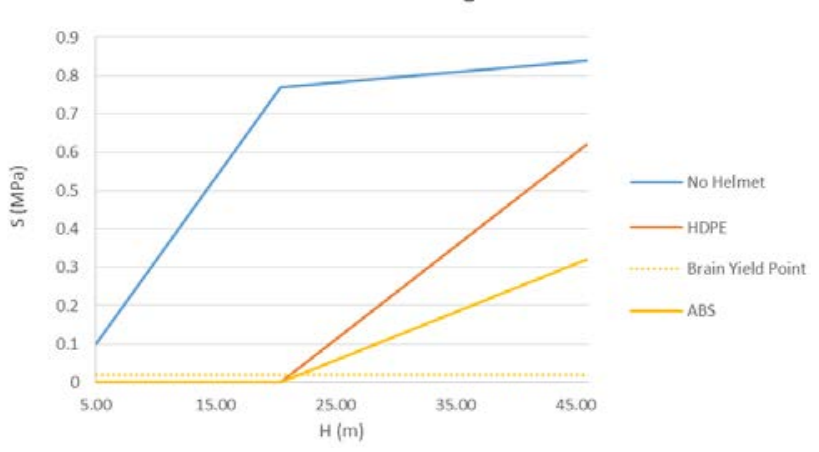

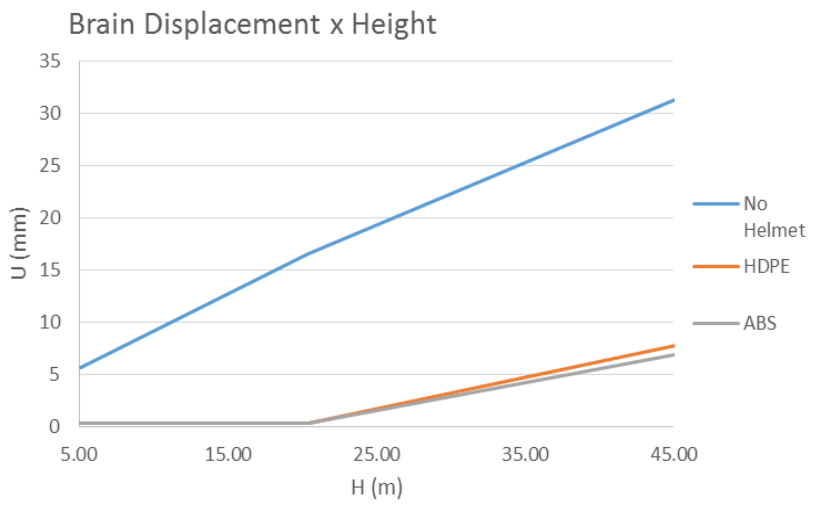

- Bike Analysis

The impact conditions of the bike helmet depend on the speed that the rider reaches the floor when hitting the head. The analysis considers three speeds: $7 \mathrm{~m} / \mathrm{s}, 8.5 \mathrm{~m} / \mathrm{s}$, and $10 \mathrm{~m} / \mathrm{s}$. In this case, the rider speed impact to the floor is the driver for this analysis. Impact speeds of riders during different types of impact can be obtained from crash data.

The helmets were tested with two shell materials: Acrylonitrile Butadiene Styrene (ABS) and High Density Polyethylene (HDPE).

The simulation represents the first $1.5 \mathrm{~ms}$ of the head hitting the floor. The values of stresses and displacements in the head are shown in the following graphs and figures:
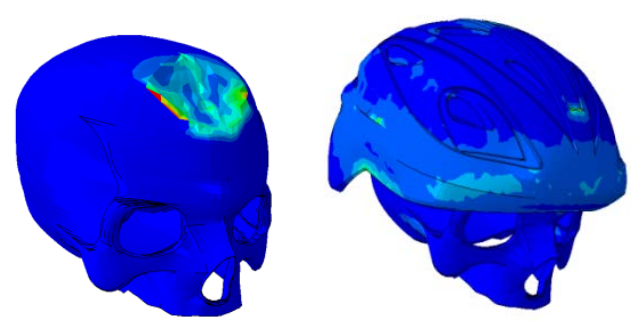

Figure 5. Bicycle simulation representative figures

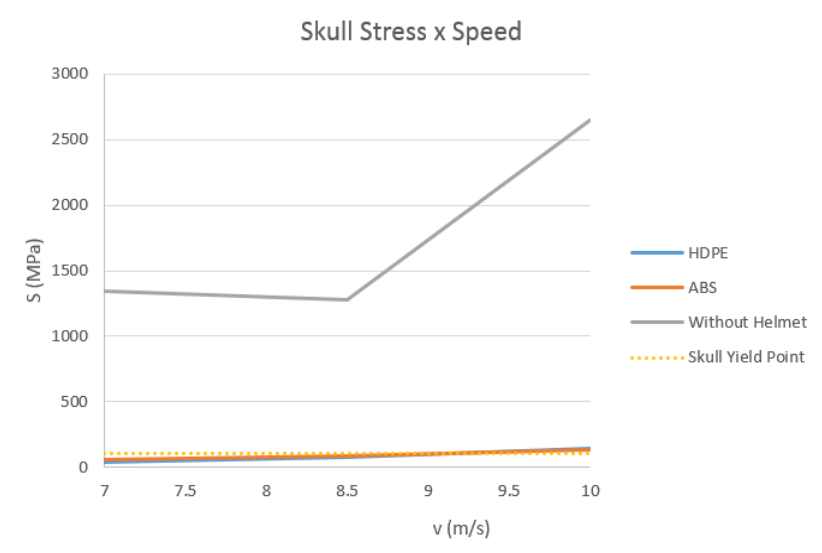




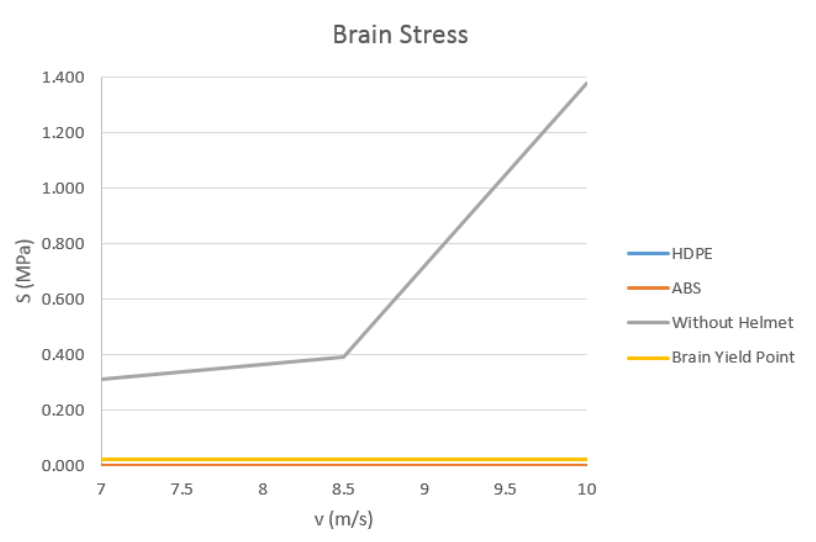

- Motorcycle Analysis

In this case, the impact condition depends on the motorcyclist speed $[7,11]$. Two speeds were studied: $20 \mathrm{~m} / \mathrm{s}$ and $25 \mathrm{~m} / \mathrm{s}$.

This simulation considers two different shell materials: Kevlar and Carbon fiber. This analysis shows the results after $2 \mathrm{~ms}$ of the head hitting the floor. The pictures and graphs below show the stresses on the head:
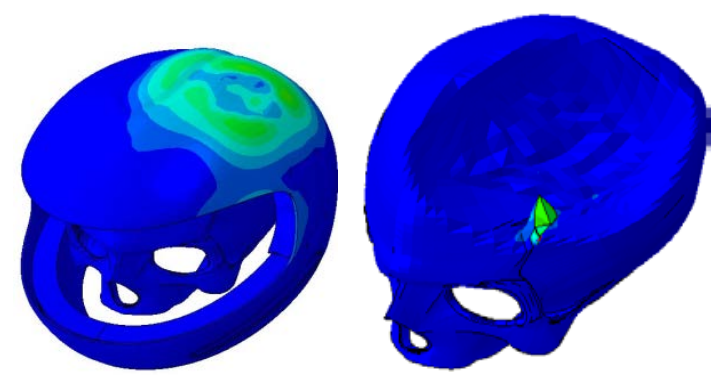

Figure 6. Motorcycle simulation representative figures

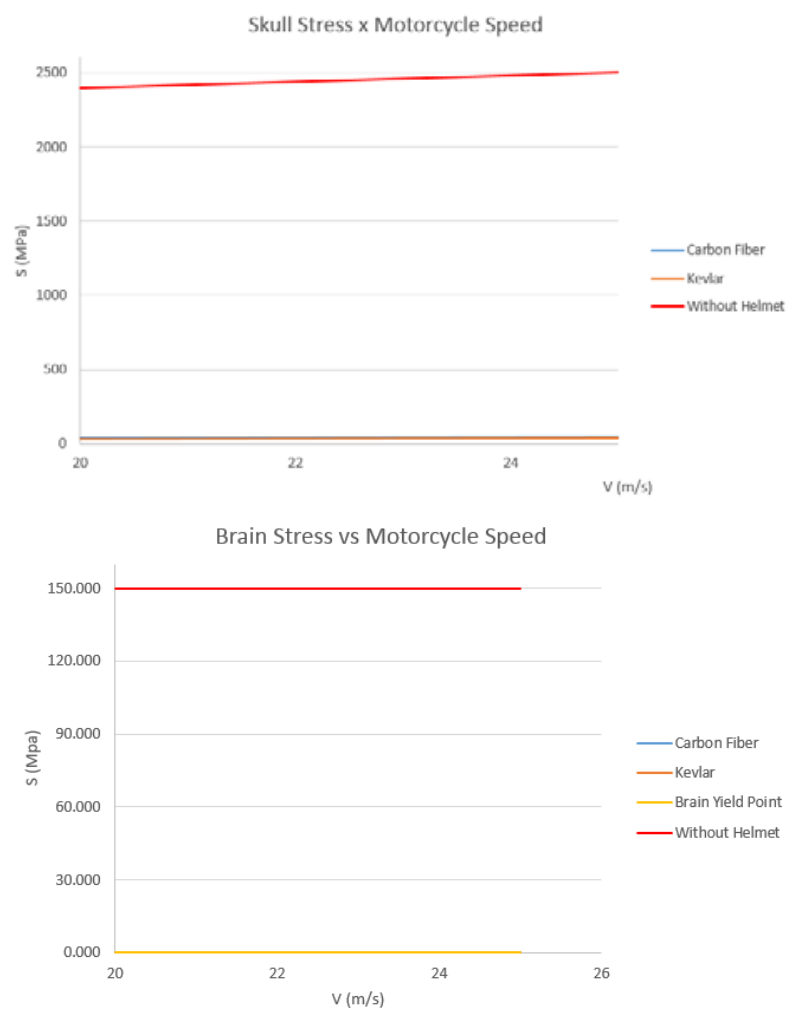

\section{Discussion}

The objective of this research was to analyze how the use of helmets can decrease the chance of serious damages on the human skull and brain. The results of each analysis are discussed below.

\section{- Construction Helmet}

Figure 3 shows the plier falling on the head, and figure 4 shows the brick hitting the head. Both cases simulate a situation with and without the helmet.

It this study, the yield stress of the brain and of the skull were considered $20 \mathrm{KPa}$, and $110 \mathrm{MPa}$, respectively. After 110MPa, the skull will reach the plastic phase, with permanent deformation.

\section{- Plier Analysis}

The stresses on the skull can be summarized as follows:

For the $5 \mathrm{~m}$ height impact, the stress in the skull with the ABS helmet is $1 \%$ of the stress without the helmet. For the HDPE helmet, this percentage is $0.4 \%$. Both helmets avoid the yield point of the skull in this height and interval. However at $46 \mathrm{~m}$, the skull will suffer serious damage. This happens because the helmet reached its own ultimate stress (30.5 MPa for HDPE helmet, and 40 MPa for ABS helmet), losing its effectiveness.

The stresses on the brain also reflect the effect of the helmet protection. In a situation without the helmet, the brain reaches its yield point with only a $5 \mathrm{~m}$ drop height. At $20 \mathrm{~m}$, the stress in the brain with the ABS helmet is $0.09 \%$ of the stress without the helmet, and for the HDPE helmet it is $0.06 \%$.

\section{- Brick Analysis}

For the brick analysis, the stresses on the skull and the brain are summarized as follows:

For a brick falling from a $5 \mathrm{~m}$ height, the stresses in the skull are smaller in the HDPE helmet than the ABS helmet. Also, the stresses in the brain are very small. However if the person does not use the helmet, he or she will receive a large amount of stress in the brain, even though the skull will not fracture.

For a $20 \mathrm{~m}$ height, the skull will reach the yield point (110 $\mathrm{MPa}$ ), with an ABS helmet, and using the HDPE helmet, the stress will be higher than the yield point of the skull. Even causing deformation in the skull, it will not affect the brain in this height and instant. This happens problably because the helmet also reached its yield point, and then it does not protect as much.

The result of the helmet action has almost similar results on the brain and skull for both materials.

In this case, the HDPE has a good behavior up to $15 \mathrm{~m}$ height, and the ABS has a good behavior up to $20 \mathrm{~m}$ height.

\section{- Bike Helmet}

For the bike helmet analysis, the results are summarized below.

It is possible to notice that the brain and the skull reach 
their ultimate stress with a $7 \mathrm{~m} / \mathrm{s}(16 \mathrm{mph})$ impact without helmet protection. This could cause concussions and serious damage on the head.

In this case the HDPE helmet had better results for $7 \mathrm{~m} / \mathrm{s}$ and $8.5 \mathrm{~m} / \mathrm{s}$ than the ABS helmet. Considering the speed $7 \mathrm{~m} / \mathrm{s}$ (an average speed), the stresses in the skull with HDPE helmet are $3 \%$ of the stresses without a helmet, and for the ABS helmet, this value is $4 \%$. For all speeds, and both materials, the stresses in the brain with the helmet are less than $1 \%$ of the condition without a helmet.

\section{- Motorcycle Helmet}

The values of stresses in the head for $20 \mathrm{~m} / \mathrm{s}$ ( $45 \mathrm{mph})$, and $25 \mathrm{~m} / \mathrm{s}$ (56mph) are summarized below:

If the person does not use a helmet, the skull and the brain reach their ultimate stress point with a $20 \mathrm{~m} / \mathrm{s}(45 \mathrm{mph})$ impact, thus causing damage.

For $20 \mathrm{~m} / \mathrm{s}$, and using the carbon fiber helmet, the stress on the skull is only $2 \%$ of the stress without the helmet. For the Kevlar helmet, this value is $1 \%$ of the stress without helmet. For the brain, the percentage for both helmets is less than $1 \%$.

The results of carbon fiber and Kevlar in the head were almost similar. The head does not suffer damage under the analyzed situation for both speeds: $20 \mathrm{~m} / \mathrm{s}$ and $25 \mathrm{~m} / \mathrm{s}$.

\section{Conclusions}

Under the analyzed circumstances, the hard hat showed efficacy up to $15 \mathrm{~m}$ height of an object drop.

For the bike study, helmets are very effective for impact protection until $10 \mathrm{~m} / \mathrm{s}$.

The results for motorcycle impact revealed that both Carbon Fiber and Kevlar exhibited similar values, avoiding deadly injury.

For more accurate results, it would be necessary to increase the refinement and quality of the meshes. In addition, it would be necessary to run more tests changing the materials of the helmets, the speed for the cyclists and motorcyclists, and also the height for the workers in the construction field. For future studies, one could vary the position the object hits the head, and also the circumstances in which the head hits the ground. Another important step is to increase the time of simulation, in order to obtain a situation closer to reality.

This research provides a good idea of the protection of the helmet. However, in a real scenario, there are many other factors to be considered, such as: the cushioning and distribution of stress provided by the skin and also hair. At last, we cannot guarantee that the brain will not suffer any damage, since the model does not have any brain fluid. The impact could make the brain shake inside the head and suffer injuries.

Also is worth noting that such data may vary according to the helmet model. Thickness, hardness and flexibility may vary as well, influencing the results.

In summary, using the software Hypermesh and ABAQUS, it was shown that all the studied helmets significantly decrease the consequences of damage in the human brain and skull. Because of that, every worker and rider should use helmets by as a conscious attitude to protect their lives.

\section{ACKNOWLEDGEMENTS}

Special thanks to the Brazilian Government and CAPES for giving us this unique opportunity to learn and develop our skills during this research through the Brazil Scientific Mobility Program (BSMP).

Special thanks to the Institute of International Education for funding the UG Research Immersion Team, ENGR-498-02.

Special thanks to the Armour College of Engineering for providing us with technical support to develop our research.

Special thanks to Tully Mijatovic for helping us during this research.

\section{APPENDIX}

\section{Plier Analysis}

i. Stresses and Displacements due impact without helmet protection

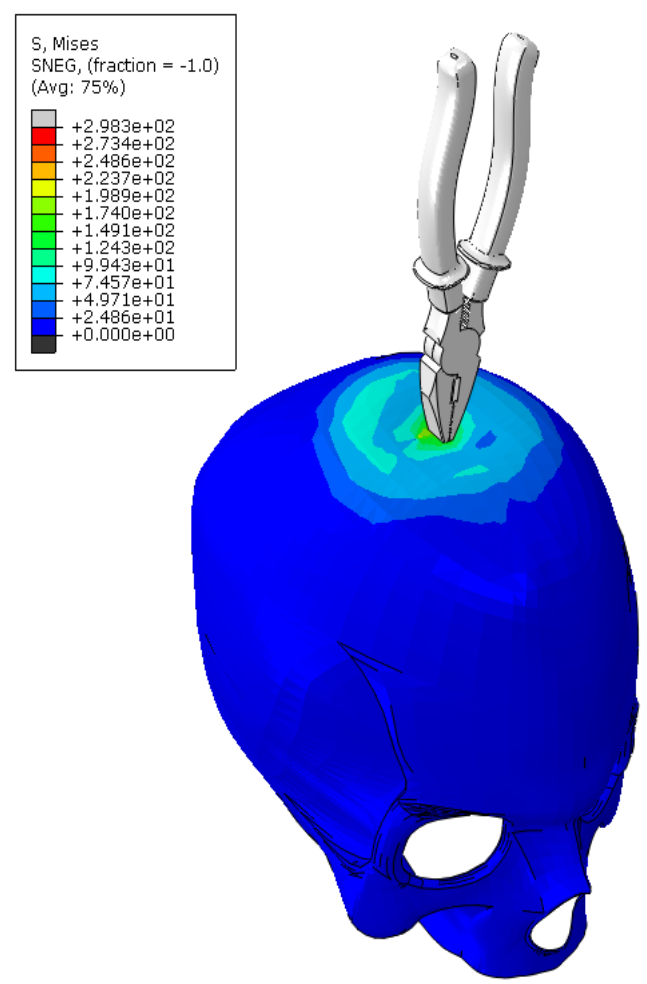



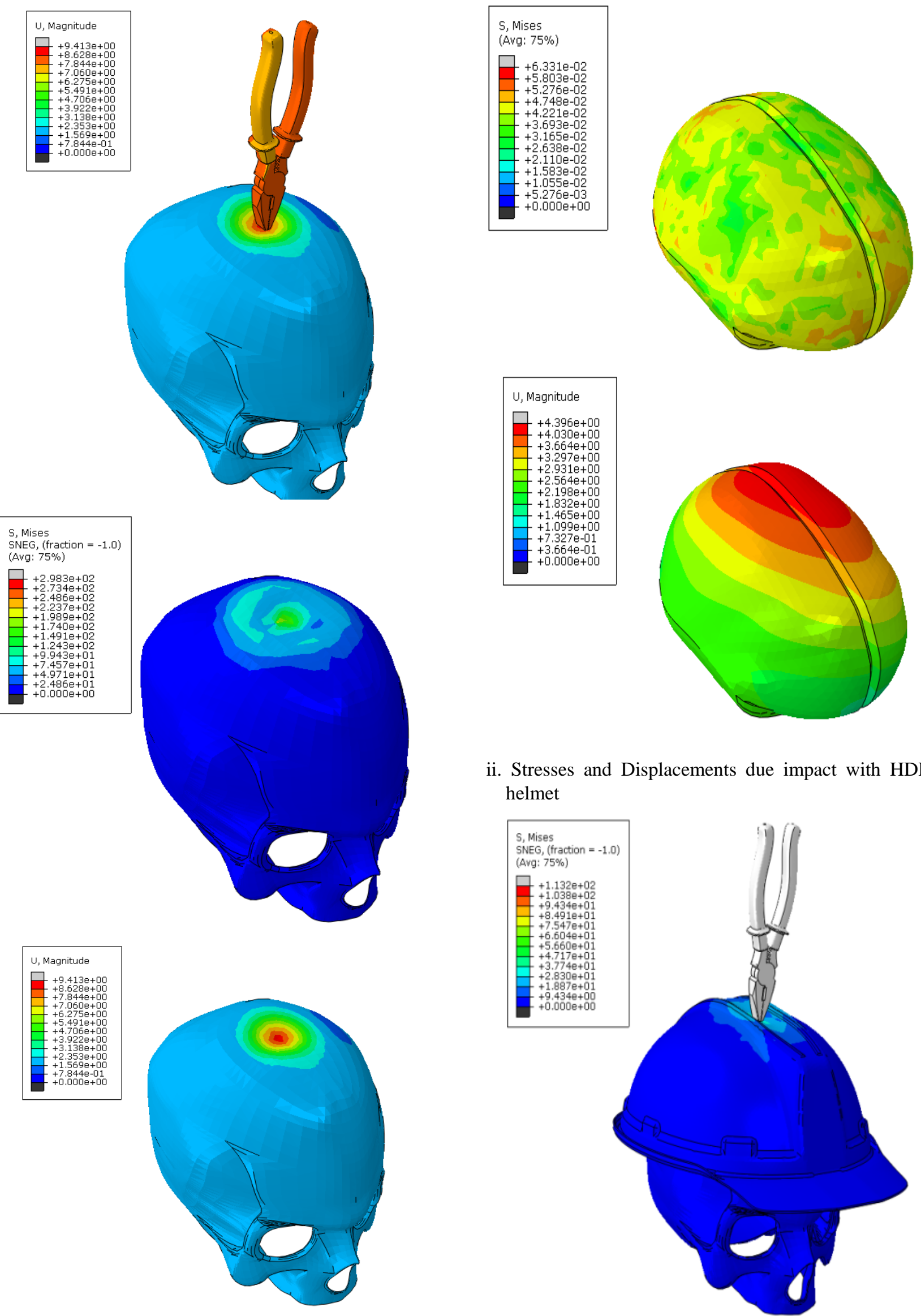

ii. Stresses and Displacements due impact with HDPE helmet

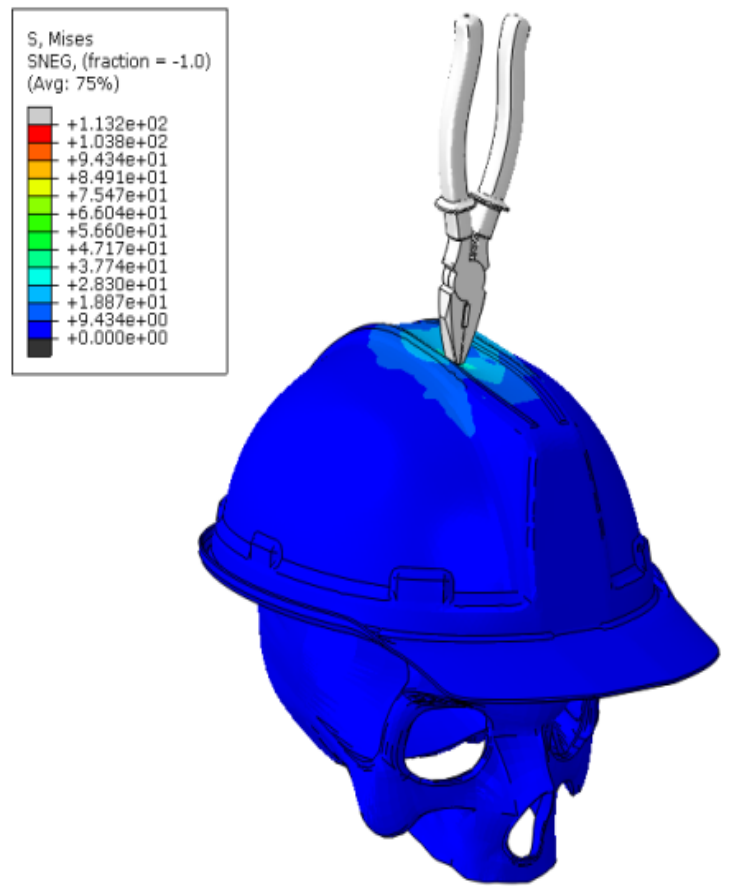



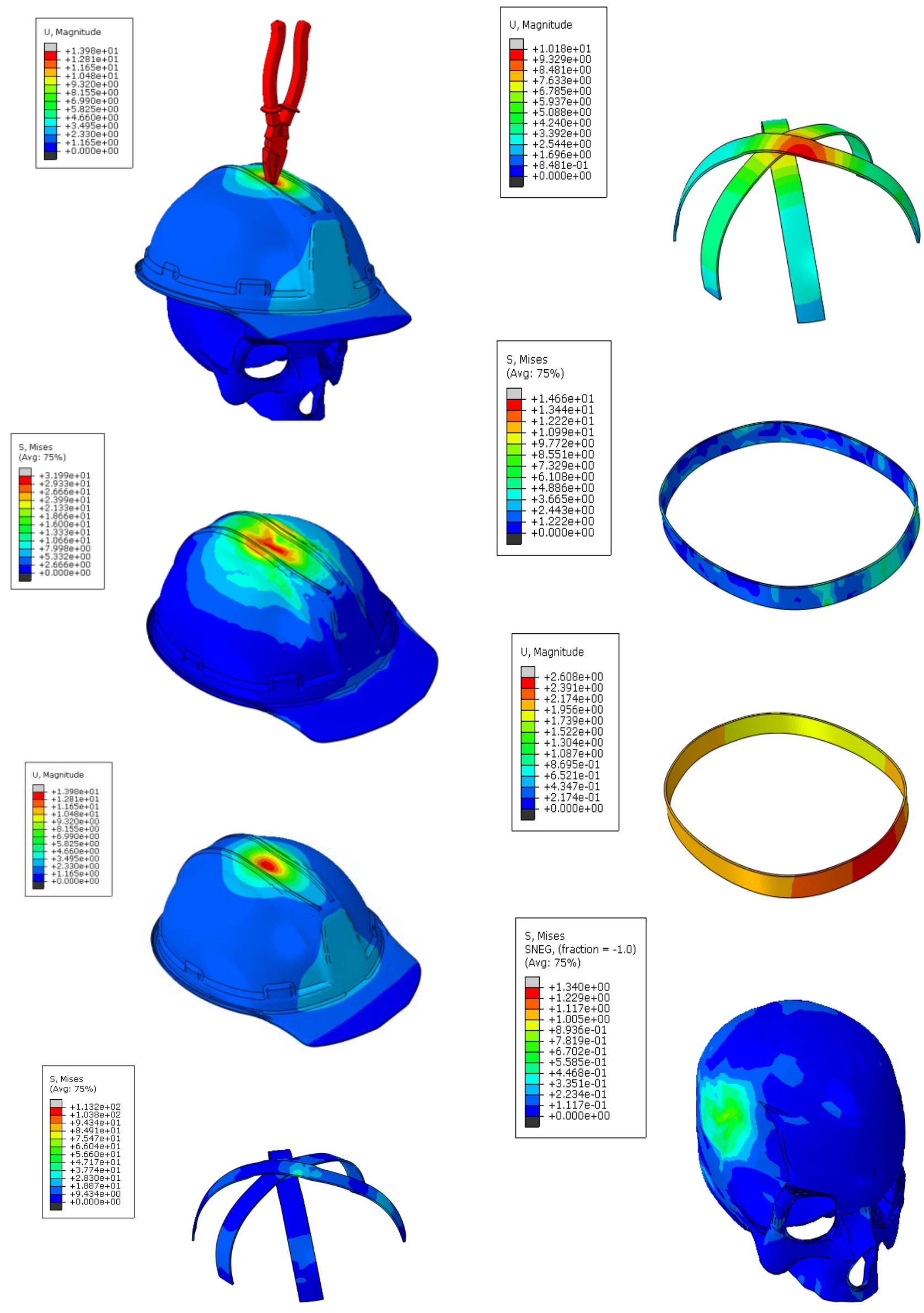

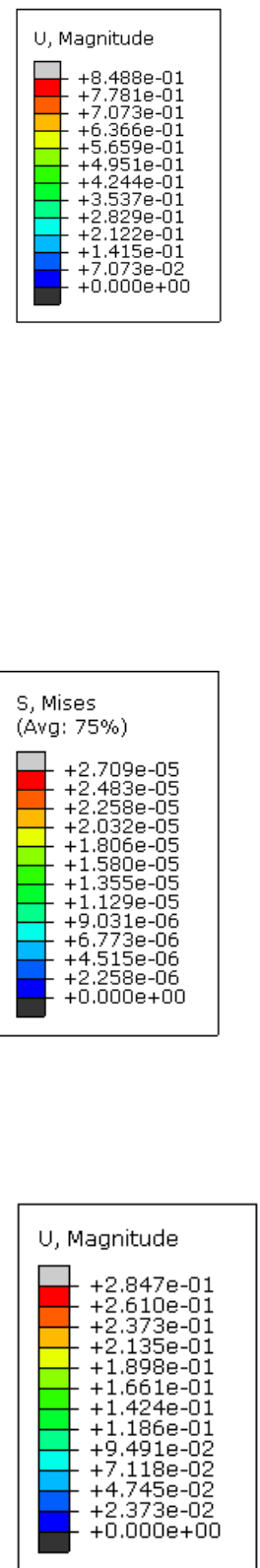
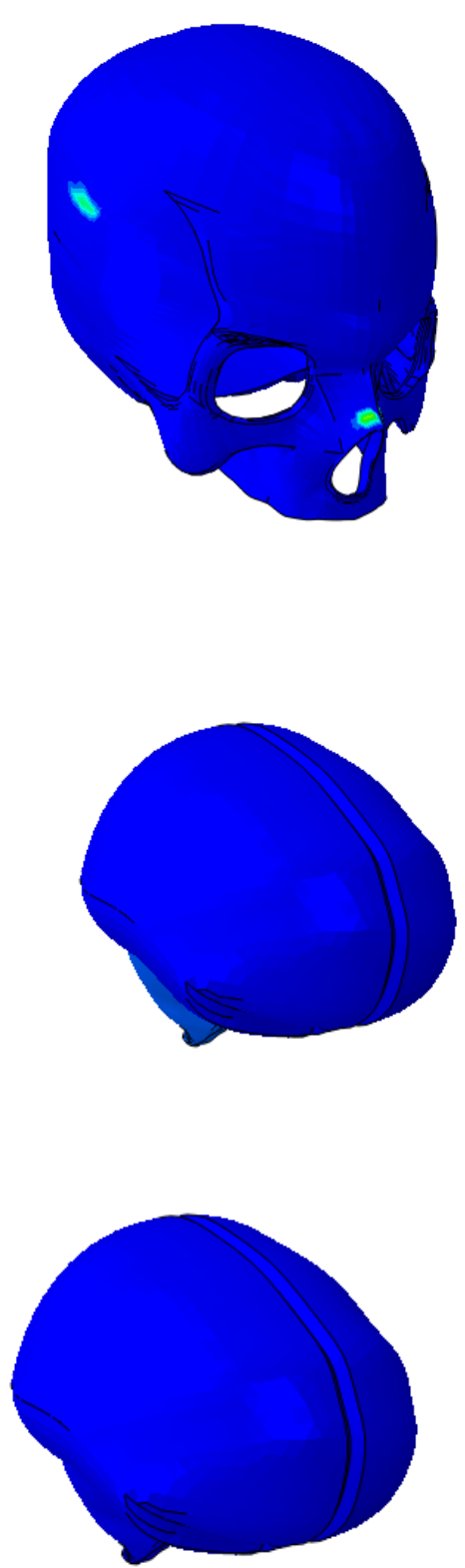

\section{REFERENCES}

[1] Ayache, N. (2004). Computational Models for the Human Body. Gulf Professional Publishing.

[2] D. H., Hobbins, J. L., Wood. (1969). Determination of Mechanical Properties of the Bones of the Skull. Retrieved from deepblue.lib.umich.edu.

[3] El Sayed, T., Mota, A., Fraternalli, F., Ortiz, M. (2008). Biomechanics of Traumatic brain injury. Elsevier.

[4] G. Duffy, Vincent. (2012). Advances in Applied Human Modeling and Simulation. Boca Raton, FL: CRC Press.

[5] GrabCAD. Retrieved from https://grabcad.com/.

[6] Kosky, P., Balmer, R., Keat, W., Wise, G. (2010). Exploring Engineering: An Introduction to Engineering and Design. Elsevier.

[7] Mahajan, P. Design of Motorcycle Helmets. Retrieved from http://tripp.iitd.ernet.in/course/lecture2013/puneet/helmet_p m32.pdf.

[8] Mat Web: Material Property Data. Retrieved from http://www.matweb.com/.

[9] M. V. Alguacil, José. (2013). Nuevos Sistemas de Protección con Núcleo de Policarbonato, contra Esperas de Ferralla y Elementos Salientes de Encofrados (Setas Protectoras). Retrieved from https://riunet.upv.es/handle/10251/27658.

[10] Mayfield Home Academy. Determining Young's Modulus of Ballistics Gel. Retrieved from Mayfieldha.com.

[11] Smith, J., Frank, T., Fowler, G., Werner, S. Motorcycle Crash Testing and Reconstruction. (2012). SAE International.

[12] S. P., Narayanan, M., Sirajuddin. (2013). Properties of Brick Masonry for FE Modeling. Retrieved from http://www.ajer.org/papers/rase-2013/volume-1/B12013061 1.pdf. 